\title{
The Borg-eye and the We-l. The production of a collective living body through wearable computers
}

\author{
Nicola Liberati ${ }^{1}$
}

Received: 30 October 2017 / Accepted: 20 March 2018 / Published online: 24 March 2018

(c) The Author(s) 2018

\begin{abstract}
The aim of this work is to analyze the constitution of a new collective subject thanks to wearable computers. Wearable computers are emerging technologies which are supposed to become pervasively used in the near future. They are devices designed to be on us every single moment of our life and to capture every experience we have. Therefore, we need to be prepared to such intrusive devices and to analyze potential effect they will have on us and our society. Thanks to a phenomenological and postphenomenological analysis, we will show how these technologies are able to generate a new collective subject with its different collective needs and appetites by merging the living body of many subjects into one. The world becomes dwelled by these new collective subjects, and we will feed their own peculiar needs.
\end{abstract}

Keywords Phenomenology $\cdot$ Postphenomenology $\cdot$ Mediation theory $\cdot$ Embodiment relations $\cdot$ Wearable computers . Collective subject

\section{Introduction}

The aim of this work is to analyze wearable computers from a phenomenological and postphenomenological perspective to study the constitution of a collective subject through these devices.

Wearable computers are emerging technologies which are going to be pervasively used in the near future. Therefore, it is mandatory to analyze them and to understand how they will mould our society and the world where we live. We will show how these technologies are able to generate a new collective subject with its different collective needs and appetites by merging the living body of many subjects into one.

This article will be structured in four main sections:

1. Section 2 will introduce wearable computers by taking into account the Google Glass.

2. Section 3 will focus on how wearables can be in embodiment relations with the subjects thanks to postphenomenology.

Nicola Liberati

liberati.nicola@gmail.com

1 Department of Philosophy, University of Twente, Enschede, The Netherlands
3. Section 4 will be on the effects wearables will have on the subjects and how it will allow the constitution of a collective subject.

4. Section 5 will show the limits of our analysis and the actual problems it faces according to the present development of the technology.

\section{Introduction on wearables}

To start our analysis, we need to introduce what a wearable computer is or, at least, what we intend with this term.

Our society is overwhelmed by computers. They are literally colonizing our world, and computers will continue to become much more powerful year after year (Mack 2015). Their dimensions will decrease, and we will be able to place them in our surrounding by making them unnoticeable or invisible to the users. Everything will be deeply intertwined with computers thanks to their reduced dimensions and their reduced costs and so our world will soon become "ubiquitous" (Weiser 1993a, b; Liberati 2016a, 2014; Rhodes et al. 1999) and fulfilled with digital technologies in the way Mark Weiser predicted (Weiser 1991; Weiser and Brown 1996).

As a direct consequence of this "ubiquitousness," even our clothes will embed microprocessors which will have their computing capability intertwined even within the fibers of 
the tissue (Kiourti et al. 2016). ${ }^{1}$ Thanks to the development of such kind of technologies, it is possible to design wearable computers which can be actually worn by the subjects. Wearable computers can have different shapes and different functions (Barfield 2015). The only limit we set to consider a technology a wearable computer is its "wearableness" and the presence of a computer in it. Therefore, as we can imagine, we are dealing with really a wide range of technologies which are designed for many different functions and needs.

To tackle this wide range of possible applications, we will refer only to one possible usage. We will focus our attention on the possibility of recording and sharing visual experiences.

\subsection{The Google Glass}

There are many different kinds of wearables which are designed for many different purposes such as watches like the Apple watch by Apple, glasses like JINS MEME by JINS, rings like RingU, bracelets like Jawbone UP3 or FitBit Charge 2, and jewellery like CUFF and Misfit. Among so many different devices, we will analyze just one device: the Google Glass.

The reasons for such a choice are easy to deduce.

1. It inspired many new prototypes and put a strong push towards the design of wearable computers. Thus, even if it was withdrawn from the market, it was influential.

2. This technology has been designed to become pervasive by keeping an eye to many factors like its cost, its weight, its efficiency, and by being designed as a fashionable object.

3. It has very simple elements mounted on it, and so its analysis can be limited to a few elements without taking into consideration many sensors.

4. It already went off the market, and so its life is already ended. We do not risk to develop an analysis on a device which will change in the future.

The Google Glass is composed of few elements such as a semi-transparent screen, a camera, and a microphone. We will focus our analysis only on the camera, because there are many works on it and because it relates expressively to sight which is one of the most important senses in phenomenology. ${ }^{2}$

Thanks to this device, it is possible to capture what the subjects wearing the device are seeing and to share it with

\footnotetext{
1 Wearable computers are not merely the ones which become intertwined into our clothes, but they are also devices meant to be worn by users like bracelets, watches, and neckless.

2 The importance of sight does not come from its place in the constitution of the subject. Sight is not the most important sense (Husserl 1971). However, it is the most studied.
}

other subjects. ${ }^{3}$ It is not surprising that the first applications were created just to exploit this potentiality and to allow distant users to "see" what the subjects wearing the Glass see. For example, Diane von Fürstenberg used this feature of the Glass o share the experience of the models walking down the catwalk with an entire audience. ${ }^{4}$ The audience could visualize the data captured by the Glass worn by the models. Moreover, thanks to this technology, it is possible to share this experience in real time which means connecting directly an entire community to the experiences lived by the wearing subjects. For example, the NBA team Sacramento Kings allowed the entire audience to experience what the NBA players were experiencing thanks to the use of the Glass. ${ }^{5}$ This way of sharing of the first point of view experiences has been successfully used for education. For example, the Glass has been used to help doctors to share what they were seeing during a surgical operation (Champeau 2014). ${ }^{6}$

The Glass, and with it every other wearable technology designed in the same way, allows distant subjects to see what happens in another part of the world.

This aspect is not new, and it is pursued by other technologies like television. When there is a live interview, the audience accesses the scene from the same point of view created by the camera in the studio. However, in the next sections, we will show the difference with these previous technologies and the peculiarities of wearable computers.

\section{Technology and the living body}

A long tradition suggests that technology can become part of the subject's living body $[$ Leib $] .^{7}$ Postphenomenology clearly states that there are some technologies which can

\footnotetext{
3 The camera of the Glass is designed to capture the scene according to the point of view of the wearing subject with the same field of view (Hwang and Peli 2014).

${ }^{4}$ See, for example, http://www.dvf.com/world-of-dvf/post/?cid=blogpost-4471 (Accessed July 28, 2015) or https://www.youtube.com/ watch? $=30$ Pj131cyDY (Accessed May 29, 2015).

${ }^{5}$ See http://www.nba.com/kings/news/sacramento-kings-become-first -professional-sports-team-stream-live-google-glass. Obviously, the players have different experiences from the people watching the game through the wearable, since they have the kinaesthetic sensations of movement related to their bodies. However, these devices generate a connection between the experience of the players and the ones of the watchers.

6 The power of these technologies to "track" and record any moment of the subjects' lives is rising many issues related to the privacy of these data (Ghovanloo and Huo 2014). Even, in the case, the data were locally stored (Van Kleek and O'Hara 2014), these technologies make the subject "trackable" (van den Eede 2015).

7 We use the term "living body" in the phenomenological conception of "Leib" as the body which perceives as opposed to the Körper (Husserl 1989, III:152-153; Liberati 2012).
} 
become part of our living body by being in an embodiment relation with the subject (Don Ihde 1990; Verbeek 2005, 2009; Wellner 2015). The classic example is a pair of glasses which allows the subject to see through the lenses and to be directly connected with the object in front of them (Don Ihde 1990).

Without going into details of this analysis, which would bring us far away from our original topic on wearable computers, we can say that the intentionality of the subject flows freely towards the object without being stopped by the device as if it was a part of the subject's body. The device "withdraws" allowing the subject to be directly oriented towards the object. Therefore, the classical perceptual pole of a subject has to be turned into a symbiotic union of a subject plus the technology (Don Ihde 1990, 86):

\footnotetext{
Classic pole : Subject $\rightarrow$ World

$\Downarrow$

Embod. rel. : (Subject-Tech) $\rightarrow$ World
}

The technology is in an embodiment relation with the subject, and every action and perception has to be considered deeply affected by the technology used. The glasses allow the subjects who are wearing them to change their own perceptual capabilities. Their perception is partially "enriched" by the new details of the objects obtained thanks to the optical corrections and modifications made by the lenses. ${ }^{8}$

The living body, according to the phenomenological tradition, is not restricted to the mere perception, but it is deeply related to other aspects of the subject's life. As highlighted by Husserl, the living body is the "zero point [Nullpunkt]" (Husserl 1952, IV:158; Summa 2014, 213:252-265) of orientation from which every action is originated and the matrix by which every action is shaped and made possible.

By modifying the body of the subjects with a technology in embodiment relation, we modify also all the other aspects related to it. For example, it is well known that the space perceived as "reachable" by the subject, which is the subject's peripersonal space (Farnè et al. 2007) can be shaped thanks to the usage of a technology. Just by grabbing a stick, it is possible to modify our peripersonal space to make the "distant" objects "close" objects. We have a modification on how the world is given to the subjects by the usage of technologies. Moreover, even the subject's appetites change

\footnotetext{
${ }^{8}$ We are not thinking of this technology as something which "betters" our "naked" perception, because many different elements are introduced such as chromatic aberrations and distortions (Liberati 2016b).
}

because of this technological modification. ${ }^{9}$ The world shows new different faces to the subject and so new things become appetible, while others reduce their attractiveness, and they fade away.

The camera, as the pair of glasses, can be conceived in an embodiment relation with the subject. The subject looks through the camera, and its intentionality flows through it towards the external object just as in the case of the pair of glasses. The camera and the glasses work in the same way, not only because they interact with the same sense, but also because they both withdraw. For example, photographers, even if they use the distortion produced by the lenses to get creative shots, are in an embodiment relation with the camera and their intentionality is not oriented towards the tool, but towards the subject of the photo. ${ }^{10}$

With glasses and cameras, ${ }^{11}$ the perceptual organs of the subject are extended through them and the devices become part of the subject's body (Liberati 2014). ${ }^{12}$

\subsection{Wearables and living body}

The camera of the Google Glass works in a similar way. It allows the subject to perceive through it. However, there is a difference. The subject who is looking through the device is not the same who is wearing it. ${ }^{13}$

\footnotetext{
${ }^{9}$ Even if here we are using the term appetite in a general way to identify any kind of inclination and attraction of the subjects towards elements in the world, we can also highlight how the use of digital technologies is literally changing the way we eat and to be on a diet (Spence et al. 2016; Riva et al. 2016).

${ }^{10}$ It is famous example of the "Kinoeye" theory by Dziga Vertov (Vertov 1984b, 5-6) who thought the lens of the camera as a kind of evolution of the human eye (Vertov 1984a).

11 This effect would be increased if the devices would be more immersive, so that the subjects would enjoy the experiences lived by the other subjects without the intrusion of other elements in it.

12 The embodiment relations generated between camera and filmmaker and between camera and watcher are well studied in film studies starting from a phenomenological point of view. The filmmaker and the watcher extend their eyes through the camera which provides them a technological mediated point of view (Sobchack 1992, 195; Zimmer 2015, 90).

${ }^{13}$ In this paper, we will not refer to the extended mind theory (Andy Clark 2003, 2010; Andy; Menary 2010; Hauskeller et al. 2016), because we will refer explicitly to postphenomenology, and these two positions cannot be easily compared. Even if they work on the same topic and they both analyze the same theme, they have different approaches. The main critic made from the postphenomenological perspective is that extended mind theory considers human beings and technology as ontologically distinct categories (Kiran and Verbeek 2010) while, according to postphenomenological framework, they should be considered tightly intertwined. However, we are not interested in the details of this distinction. For the relation between extended mind and postphenomenology, see (Ihde 2003; Evan et al. 2007, 2008; Clark 2007, 2008; Evan et al. 2015).
} 
In the case of the optical glasses, the subject who wears the technology is also the subject who is in an embodiment relation with the technology. In the case of the Glass, the subject who is wearing the technology is not the one who looks through the camera, or, at least, they are not the only ones allowed to look through it. The camera is accessible by distant subjects who have access to the database of the device, and so this device allows subjects who are not wearing the devices to see through them.

From a scheme composed of three elements, we have the introduction of a fourth element in it: the subject who looks through the camera who is a beholder looking at the actions performed ( $\left.S_{\text {Beholder }}\right)$. Therefore, we have a subject of a community who is in embodiment relations with the technology worn another subject $\left(\mathrm{Tech}_{S_{\mathrm{We}}}\right)$ :

Classic glasses : $\left(S_{\mathrm{We}}-\right.$ Tech $\left._{S_{\mathrm{We}}}\right) \rightarrow$ World

Wearables : $\left(S_{\text {Beholder }}-\right.$ Tech $\left._{S_{\mathrm{We}}}\right) \rightarrow$ World

We have a scission between the functions. Even if these devices work as technologies in an embodiment relation, because they allow a distant subject to see through them; the beholder is not the person who carries the devices and who has them mounted on him. The technological extension of the perceptual organ of the beholder is attached to the flesh of the wearing subject. It is possible to have subjects, seated on their comfortable chairs in their own apartment, who perceive what another subject is living just by having their own technologically mediated eyes mounted on the other's living body.

In addition to this dislocation of the perceptual organs of the subject, we have another important difference with the case of the classic optical glasses. With the Glass, the perception is not limited to a single subject, many subjects can access the same camera at the same time. With optical glasses, only the wearing subject is able to look through them:

$\left(\left(S_{1}, S_{2}, \ldots, S_{n}\right)_{\mathrm{Be}}-\right.$ Tech $\left._{S_{\mathrm{We}}}\right) \rightarrow$ World

As in the previous case, we have a subject who is in an embodiment relation with the technology. However, now, we have many different subjects in relation to the same device instead of one. Their eyes are embodying the same device and they collimate within the same camera. Their organs become technologically embedded, because they start to work in symbiosis with the device and, in this case, a single digital camera works in symbiosis with many different eyes originally part of different individuals. Thanks to this collective symbiosis, we have a merging between these technologically enhanced eyes, because they co-work together with the exact same device. These subjects perceive all together through the same digital eye mounted on the wearing subject.
Instead of having a single subject who is in an embodiment relation with the technology, we have a collective eye which provides a collective perception. ${ }^{14}$

$$
\begin{gathered}
\text { Classic glasses : } \\
\left.\qquad \text { Subject }_{\mathrm{Be}}-\text { Tech }\right) \\
\text { Wearables : }\left(S_{1}, S_{2}, \ldots, S_{n}\right)_{\mathrm{Be}}-\text { Tech }_{S_{\mathrm{We}}}
\end{gathered}
$$

Thanks to this collective organ, we can start talking about a new type of subject who is the merging of many different individuals who are looking through the same technology. This phenomenon is similar to the one produced by other devices like television, where an entire audience perceives the scene through the lenses of the camera which captures the scene and through the screen of the television. ${ }^{15}$ It is possible to think of the audience as a collectivity watching together the scene (Elsner and Müller 1988) where each viewer accesses the same point of view of the camera. ${ }^{16}$

\section{Study on a collective living body}

Many subjects are merged at the perceptual level by having the same devices as the ending part of their perceptual organs. A new collective subject is generated by the creation of a collective digital living body. Many eyes turn into one and a collective subject raises thanks to this merging. ${ }^{17}$

The idea of a collective subject which is composed of different subjects merged together is not new in philosophy either. Even if its "classification" has been identified with different names, this theme has a long history. ${ }^{18}$

\footnotetext{
14 There is already a study on collective brain based on Google Glass (Heylighen 2013). However, these works are not about the creation of a collective body, and so, we cannot base our analysis on them completely.

15 On collectivities generated through the use of television, see (Frosh 2011; Stiegler 2003).

16 We will see in the next sections the difference with television.

17 The idea of a collective subject which is composed of many different subjects merged together is rising interest in computer and cognitive sciences (Kramer et al. 2014; Kyriazis 2015b, a; Grau et al. 2014; Blumberg and Michelucci 2013). These works are expressively related to the merging of many individuals into one single collective subject, such as in the case of (Pais-Vieira et al. 2015) where three monkeys are connected through their brain, and they act together moving a remote robotic arm. However, these works focus on computer cognitive sciences and not directly on phenomenology. Thus, even if they are interesting to show the path which we are walking, they cannot be directly used in our analysis.

${ }^{18}$ Pope Innocentius IV, maybe, was the first who recognized the group as a persona creating the concept of "legal personality [persona ficta]" for legal eschews (Pettit 2014). Even recently, the debate on the existence collective subjects is still lively disputed (Searle 1990; Gilbert 2007; Pettit 2004; De Vecchi 2014).
} 
Many different analyses have studied the phenomenon of social bounds which make people act as parts of the same "higher order" subject such as in the case of a group or a community. The subjects who are part of this higher order subject move and act together achieving a common goal. In this action, their intentionality is merged together in a collective one. However, these analyses are related to the study of a collective subject quite different from the one deriving from our technological production.

\subsection{The collective subject}

The idea of a collective subject ${ }^{19}$ which groups different subjects into one is always taken into account starting from the "basic" actions of the single subjects taken in their singleness. Multiple subjects act together, and their actions are orchestrated as a single one at a higher level (Salice and Taipale 2015). For example, in the case of the group "soccer team", the single subjects act together to achieve a common goal.

There are many different positions regarding the nature of the group. Some analyses state that the collective subject can be reduced to the subjects acting in it and others defend the opposite position, arguing that this new collective subject has to be considered as one and cannot be reduced to the single individuals. However, even the most "extremist" analyses which think of the group as a new being which is irreducible to the subjects found this new entity on the actions of the single subjects' living bodies. The collective living body is actually founded on the many living bodies of the subjects taken in their singleness. However, we cannot accept these analyses, because they have a collective subject composed by multiple living bodies taken as singles.

Max Scheler, who seriously analyzed the collective subject or, using his terminology, the collective person [Gesamtperson] (Salice 2015; Kelly 2011; Scheler 1972), considered it as something generated starting from the single subjective experiences. In his analysis, the subjects who are part of the collective person are described as acting as singles who are "unconsciously" performing a collective action (Salice 2015). Thanks to this starting point, he managed to save the irreducibility of the collective person without saying that there are perceptions not related to the single subjects. The action is originated by the collectivity, but it is performed by the many hypnotized subjects taken in their singleness (Scheler 1973). Even if we have an action originated from the collectivity, the action is actually performed by single subjects acting as hypnotized singles. Thus, every single experience of the collective person is deeply rooted in the

\footnotetext{
19 We still have to think of this term as equivalent to other different terminology which actually relates to the same theme such as collective intentionality, collective mind, and many other similar terms.
}

single subjects taken in their singleness. The collectivity is not only founded on the singles, but the actions are performed by the singles individuals thanks to their single living bodies.

We cannot accept this element, because, with wearables, we have a collective living body which is not reducible to the single individuals. The collective subject is able to directly perceive as a collectivity without being founded on the single subjects' living body for simple reasons.

First, the collective subject does not perceive "through" the perception of the single wearing subjects taken as singles, because they are not the ones that look through the technology; they are just the mere carriers.

Second, the collectivity does not see "through" the beholders as singles, as well. When the beholders perceive through the technology, they are in an embodiment relation with a technology which is also in an embodiment relation with other beholders at the same time. This "simple" element makes the sensible organ a collective organ which cannot be considered as related to the "singles". As far as we think of the perceptual organ as the composition of the eye of the subject plus the technology used, we have to think of it as a collective perceptual organ, because the technology is in the same relation with others.

The technology is in embodiment relation not just with one beholder, but with every beholder who is part of the collective subject. Therefore, when the beholders perceive through the technology, they actually perceive with a collective perceptual organ, because the technology used is a part of the body of the other beholders, as well.

Obviously, the collective perceptions are still related to the single subjects' lives and their own private perceptions. More precisely, the collective perceptual organs are still related to the position and the actions of the wearing subjects, and they are founded on the single perceptual organs of the beholders. However, they cannot be reduced to the organs of the singles, because, when the beholders perceive through the technology, they embody a technology which is already embodied by other beholders. They perceive together through the same digital eye. The organ thanks to which the beholder perceives is collective. The "eyes" of the beholders are collective eyes.

The collectivity has its own living body and this element reshapes completely its previous conception. With wearable computers, the collective subject has its own collective body without referring to single bodies in their singleness. The collective subject is irreducible to the subjects not just because the experience of the collectivity has been generated at a "higher level", but also because it has a different living body, and so it can act in the world and perceive directly.

The collective subject, thanks to wearable computers, has its own eyes. 


\subsection{Collective affections and effects on the single subjects}

As we have previously seen, the living body of the subject is not a mere object in the world which shapes our actions. It is the zero point of orientation and the generator of every action of the subjects. Moreover, it is also what allows the subject to have affections towards the world.

The world, according to Husserl, emanates affective rays related to the contrasts present in it to stimulate the subject in a certain way. ${ }^{20}$ These affections are not immutable, but they are related to the experiences of the subjects and their living body (Gooskens 2011, 184-185; Husserl 1966, XI:148-172). Thus, the usage of a technology changes the affective rays emanated from the world, because the subject becomes receptive to different elements (Husserl 1971, V:7). More specifically, a collective subject generated by the usage of a technology will make the world send rays expressively shaped for this collective subject in addition to the others.

The beholders play a double role. They are single subjects, because they live with their own living body, but, at the same time, they perceive with the collective living body and they are part of this community. Therefore, they are stimulated by both of the rays emanated from the world: the ones related to the single subjects and the ones related to the collectivity. They become stimulated by these affections made for the collective subject, and the aspects of the world which are "important" to the collective subject will be peculiarly powerful for them too. The objects which are attractive for the collective subject will start to be attractive for the single subjects, as well.

One important aspect with wearable computers is that the beholders are not only merely single individuals. They can be the wearing subjects too. We always made a clear distinction between the wearing subjects and the beholders, because we wanted to highlight their different relation to the technologies. However, the wearing subjects can be perceived through the wearables and vice versa. Even if there is a clear distinction between the two roles, it is possible to have subjects playing both of them.

We can fully appreciate the difference with technologies like television, which provide many users with the same perception of a scene. Television can provide subjects with the same perception and so it can generate beholders looking through the device as a collectivity. However, it is not possible to have these beholders wearing or carrying the devices by themselves. Thus, it is possible to be wearing

\footnotetext{
20 The affective rays are not rays generated by the object without the presence of the subject, but it is the way which the object is given to the subject. On the nature of these affective rays, see (Biceaga 2010, 60:33; Husserl 1971, V:§ 25).
}

subjects and beholders at the same time. For example, in the case of television, the users have just the access to the scene and they cannot move the camera around. The audience is fixed in one place and the collective organ produced by the television is out of their control (Mann et al. 2003). With wearables, it is possible for the beholders wearing the collective devices to become more "active", because they are the ones carrying the collective organs.

From merely "passive" and "voyeuristic" beholders, through wearable computers, they become the ones who carry the devices and move them in the world. This element provides the collectivity with the living body's zero point of orientation from which every action of the subject is generated.

In the case of the previous technologies, the "passive" beholders can only hope the subjects dealing with the camera which will act in a way which fits their collective interest such as focusing on a part of the scene instead of another one. They cannot act, directly because they are merely observing the scene. The beholders who are also wearing subjects act in the world with their single individual living body and the collective one. Thus, the rays generated by the object for the collective subject can be followed by a corresponding action made by the collective subject. The beholders can freely and collectively focus on a part of the scene or zoom on some elements, because they are the ones carrying the devices.

Thanks to wearable computers, the collective subject has not merely its own eyes, but it acts in the world thanks to its collective body.

\subsection{The Borg collective}

As we have previously seen, the classic phenomenological analysis on collective subjects cannot be applied in our case, because we have a direct collective perception by a collective living body. Therefore, to have an idea of how this collective subject looks like and to focus our attention on the possible effects which it may yield, we need an example which does not come directly from a phenomenological analysis. We will take into account the "Borg Collective" in Star Trek. ${ }^{21}$

\footnotetext{
21 "The Borg (derivate of cyborg) are cybernetic race appearing in Star Trek: The Next Generation, Star Trek: First Contact, and Star Trek: Voyager. They have been central antagonists in many plotlines and are very popular as villains. they are portrayed as having managed to integrate technology into their organic bodies to such an extent that they cannot exist without either. The Borg are also presented as a collective society, meaning that Borg "drones" do not register as individuals - they are a part of a group mind, which control each drone's actions." (Consalvo 2004, 182). Alternatively, the description made by Arras "The Borg, a hive of cybernetically enhanced humanoid drones, explores the universe in search of interesting new cultures and technologies, which they promptly conquer and incorporate into their neural network en route to their goal of ultimate perfection." (Arras 2009).
} 
This futuristic alien race aims to "assimilate" other forms of life to reach perfection. However, what is more important for our analysis, is not their strive to perfection, but their pervasive use of technologies which runs through their entire bodies.

Thanks to a massive use of technology implanted in their flesh, every component of the Borg is always connected to the community called the Collective. This connection enables them to share their experiences and their thoughts in real time. What a single Borg thinks is thought by every single Borg of the Collective and what a Borg sees is instantly seen by everybody. ${ }^{22}$

In this dystopian scenario, the single Borg subjects, who are reduced to mere "drones", cannot refer to themselves as an "I", but only as a collective "We", because they share their entire life and their bodies with the Collective. Therefore, we have the annihilation of any individuality related to the existence of the singles in favor of the collective coexistence of the many. Every single subject is turned into a "we-subject" connected to the collectivity.

Without starting to argue on the possibility or on the impossibility of this futuristic scenario, we can use it as an example to highlight possible effects these technologies will have on our society.

Our wearable computers are designed to share experiences and, at first sight, they could seem like a sort of underdeveloped Borg-like technology which will reach its full potential only in the future by becoming more powerful and pervasive just like the Borg one. We can ask if wearable computers are going to turn ourselves, or our future generations, into Borg-like subjects and change our society into something similar to the dystopian Borg society.

Are we going to be "we-subjects" without any kind of individuality and with collective Borg-like organs running through our body? Will we be able to refer to ourselves as single "I" or we are going to be mere plural subjects merged together in a "We-I."

To answer this question, we need to focus our attention on the differences between our technologies and the one used by the Borg.

Our wearable computers are designed to be removable from the body quite easily. Every wearable is, by definition, something which is worn as clothes and so the subject has the power to take them off. The Google Glass, for example, can be removed by just taking it off from our nose. ${ }^{23}$

\footnotetext{
22 This idea was risen by posthumanism too (Roskies 2005; Andy; Clark 2003).

23 This difference can be highlighted even more if we think of the two relations between the users and the technologies generated in the two cases. In the case of the Borg, we have cyborg relations where the technology cannot be disjointed from the human body, while, in the case of a person, wearing a wearable computer, we have an embodiment relation where the tool becomes part of the body during the use. See (Don Ihde 2008; Verbeek 2008).
}

In the case of the Borg, we have quite a different technology. It is not removable from the body and, moreover, it is not something worn, but it is intertwined with the very flesh of the drones so deeply which is not removable without causing their death. Therefore, the Borg technology is always mounted on the subjects and it cannot be separated from the subject's body. Moreover, it is always active. The subjects cannot turn it off without losing themselves and when the drones' body is violated by unplugging them from the Collective they tend to lose their lucidity, because they have to learn how to live as single subjects as if they were not individuals before the disconnection. ${ }^{24}$ The drone cannot have private perceptions because of their always connection to the Collective thanks to a technology which is always on them and always active. Their living bodies are always merged into the one of the Collective.

In our case, the wearable computers are not always mounted on the subject, and they can be easily deactivated by turning them off. This "simple" difference makes the two technologies very distant. The wearing subjects can disconnect the collective perceptual organ from their own single bodies. In this way, they can free themselves from the collectivity. The beholders can turn the device off as well and so they can stop to perceive through the collective organ. The wearable computers are "merely" attached to the single subjects' body, and so, even if they provide a collective body, they do not turn the single bodies into the collective one, but they just add the collective organs to the single ones.

The Borg does not have "private" perceptual organs. Everything in the Borg drone is collective. The subject using wearable can have private perceptual organs by simply removing the devices. In the Borg case, we cannot have a single subject any longer. The wearing subject is always a beholder because they are always looking through the device, and so the single subject disappears completely into the collective one. In the case of the wearable computers, we do have the creation of a collective subject which shapes our world, but, at the same time, we do not get rid of the original single subjects. We have a co-existence of two different types of subjects in the same world.

However, we need to keep in mind what the Star Trek example seems to suggest, without taking into consideration every single aspect of this science fictional world. This fiction clearly shows how the world could start to be dwelled by a new collective subject which will develop their own peculiar life with their habits and their appetites just like normal "single" subjects do. We are not going to merge ourselves

\footnotetext{
${ }^{24}$ In the Star Trek world, the single Borg feel lost when disconnected from the Collective such as in the case of the disconnection of two characters of the series "7 of 9" and "Hugh" respectively in the first episode of the second season of Star Trek: Voyager and in the 23rd episode of the fifth season of Star Trek: The Next Generation.
} 
completely with others and so we will not become Borglike subjects. However, the collective body generated by the wearable computers will start to act in the world producing their own collective perceptions, their own collective actions, and their own collective needs just like the Borg Collective.

\section{Limits of this approach and of this technology}

There are possible critics and limits of this analysis.

This analysis finds its limits when it comes to deal with some elements of the living body which are not present in the collective technological one. It could seem we talked about a collective living body and a symbiotic relation between subject and technology, but we ignored some problematic elements.

First of all, our analysis is strictly related to sight, and it focuses on application working only with this sense. We completely ignored other senses. Anyway, even if we analyzed only one sense instead of taking into consideration the entire spectrum, it is possible to apply our work to any of the other senses. For example, it is possible to study hearing in the case of a technology which captures the sounds a subject hears and which shares it to a community. In addition, in this case, we have "wearing subjects" and "beholders". Moreover, it is possible to think of devices which allow people to share tactual (Liberati 2017) and taste sensation (Cheok et al. 2011) the distance. Therefore, even if the phenomenological analysis on how the subjects perceive has to be changed a bit to fit the new sense, it does not change the main structure of our work. We still have an experience of one single subject which is shared with a community, allowing the collective subject to directly perceive through the technology.

The second and, maybe, more sound critic are related to the kind of actions which the collective subject is able to do thanks to this device. The beholders who are not wearing the technologies are mere passive viewers who cannot act in the world with the collective body.

According to the phenomenological tradition, the living body of a subject should provide the zero point from which the subject can act in the world, or from which the subject can originate their "I can [Ich kann]". This technology, at the present stage of development, does not allow the beholders to act, and so it cannot be, strictly speaking, part of the living body and acting in symbiosis.

However, we saw the beholders which can be wearing subjects too. Thus, they can act in the world while perceiving through the collective body. Moreover, this "voyeuristic" limit is just related to the actual limits of our technological development. For example, it is possible to design a camera which can change orientation according to the will of the collective subject and which focuses on some elements of the scene instead of others. However, by limiting our analysis on actual technologies, we have to take this possibility as a mere hypothesis not realized yet.

The third critic is about the kind of devices which we analyzed. Even if this work does not focus only on the visual field, because we can extend it to other senses, it is limited because it is tightly related to the devices allowing the subjects to perceive through them. However, there are many other devices which are not designed to do it, but they are designed to "merely" capture and store data about the subjects. For example, the Apple watch is not designed to share perceptions, but to store data about the subjects' life such as the measure of the wearing subjects' heartbeats. For this reason, our analysis could look like restricted to few examples and not to wearable computers, in general.

We focused our attention on perception, and so, the devices which do not provide a perception are excluded. However, this limitation does not compromise our work. Our analysis clearly shows how it is possible to generate a collective living body, and so, maybe, it could be useful for studying how these data of the single subjects could constitute a collectivity and in which way they do it.

Our analysis is not complete, but it highlights some possible aspects of these technologies.

\section{Conclusions}

In the first part, we introduced wearable computers by analyzing Google Glass, and we showed how it can be used to share a visual experience with an entire community thanks to its camera.

In the second part, we studied how wearable computers can become part of the living body and how the subjects perceive through them thanks to postphenomenology. We highlighted these technologies work in a different way from the previous one, because they allow a community to be embodied with the same device. Thanks to this collective embodiment, the wearable computers generate a collective living body. This analysis is limited to the perceptual level and according to a phenomenological analysis. The analysis should be extended in other fields by analyzing the psychological issues related to such an emergence and the effects on individuality, identity, and personality generated by this new collective body.

In the third part, we showed how these technologies generate a new type of collective subject because they aim to produce a collective body. This new subject has the capability of perceiving the world directly as a collectivity without founding its living body on the ones of the single subjects taken in their singleness. We showed how the creation of such collective body has effects on the subjects being part of 
it, because they will be stimulated by the affective rays generated for the collective body in addition to the ones directed to their single ones.

Even if there are many points connecting this process to dystopian futures, these subjects do not risk to become Borg-like subjects. They are not completely merged into the collectivity, because they still have their own single bodies taken as single individuals at the perceptual level. However, it is wrong to think that they have no effects. The subjects will act and perceive as members of this new collective organism pursuing their collective goals.

The world will become dwelled by these new collective subjects which will develop their own peculiar needs to be fed.

Acknowledgements Nicola Liberati is supported by the NWO (Nederlandse Organisatie voor Wetenschappelijk Onderzoek) VICI project "Theorizing Technological Mediation: toward an empirical-philosophical theory of technology" (grant number: 277-20-006).

Open Access This article is distributed under the terms of the Creative Commons Attribution 4.0 International License (http://creativeco mmons.org/licenses/by/4.0/), which permits unrestricted use, distribution, and reproduction in any medium, provided you give appropriate credit to the original author(s) and the source, provide a link to the Creative Commons license, and indicate if changes were made.

\section{References}

Arras JD (2009) The Hedgehog and the Borg: common morality in bioethics. Theor Med Bioeth 30(1):11-30. https://doi.org/10.1007/ s11017-009-9093-5. (Springer Netherlands)

Barfield W (2015) Fundamentals of wearable computers and augmented reality, 2nd edn. CRC Press LLC, Boca Raton

Biceaga V (2010) The concept of passivity in Husserl's phenomenology. Contributions to Phenomenology. vol 60. Springer, New York

Blumberg M, Michelucci P (eds) (2013) Handbook of human computation. 1st edn. Springer, New York

Champeau R (2014) UCLA physicians use google glass to teach surgery abroad. Teaching surgeons can watch operation and comment via this tech tool. http://newsroom.ucla.edu/stories/uclaphysicians-use-google-glass-to-teach-surgery-abroad. Accessed 23 Mar 2018

Cheok AD, Ranasinghe N, Owen NNF, Hideaki N, Ponnampalam G (2011) Digital taste: electronic stimulation of taste sensations. In: Keyson DV, Maher ML, Streitz N, Cheok AD, Augusto JC, Wichert R, Englebienne G, Aghajan HK, Kröse BJA (eds) AmI. Lecture Notes in Computer Science, vol 7040. Springer, New York, pp 345-349

Ciano A (2015) The artifactual mind: overcoming the inside-outside' Dualism in the extended mind thesis and recognizing the technological dimension of cognition. Phenomenol Cogn Sci 14(1):73-94

Clark A (2003) Natural-born cyborgs: minds, technologies, and the future of human intelligence. Oxford University Press, Oxford

Clark A (2007) Negotiating embodiment: a reply to Selinger and Engström. Janus Head 9(2):585-587

Clark A (2008) The frozen cyborg: a reply to Selinger and Engström. Phenomenol Cogn Sci 7(3):343-346. https://doi.org/10.1007/ s11097-008-9105-3
Clark A (2010) Supersizing the mind: embodiment, action, and cognitive extension. Oxford University Press, Oxford

Consalvo M (2004) Borg Babes, drones, and the collective: reading gender and the body in Star Trek. Women's Stud Commun 27(2):177-203. https://doi.org/10.1080/07491409.2004.10162 472

De Vecchi F (2014) Three types of heterotropic intentionality. A taxonomy in social ontology. In: Institutions, emotions, and group agents. Springer Netherlands, Dordrecht, pp 117-137. https:// doi.org/10.1007/978-94-007-6934-2_8

Elsner M, Müller T (1988) Der Angewachsene Fernseher. In: Materialität Der Kommunikation. Suhrkamp, Berlin, pp 392-415

Farnè A, Serino A, Làdavas E (2007) Dynamic size-change of perihand space following tool-use: determinants and spatial characteristics revealed through cross-modal extinction. Cortex 43(3):436-443. http://www.sciencedirect.com/science/article/ B8JH1-4S03J10-H/2/c5f22e26687db9de4d4866355a064022. Accessed 23 Mar 2018 (Varese, Italy, Tipografica Varese)

Frosh P (2011) Television and the imagination of memory: life on mars. In: On media memory. Palgrave Macmillan UK, London, pp 117-131. https://doi.org/10.1057/9780230307070_9

Ghovanloo M, Huo X (2014) Wearable and non-invasive assistive technologies. In: Sazonov E, Neuman MR (eds) Wearable sensors. Fundamentals, implementation and applications. Academic Press, Oxford, pp 563-590. https://doi.org/10.1016/ B978-0-12-418662-0.00009-X

Gilbert M (2007) Searle and collective intentions. In: Tsohatzidis SL (ed) Intentional acts and institutional facts. Theory and Decision Library, vol 41. Springer Netherlands, Dordrecht, pp 31-48. https://doi.org/10.1007/978-1-4020-6104-2_1

Gooskens G (2011) Towards a responsive subject: Husserl on affection. In: Tymieniecka A-T (ed) Transcendentalism overturned. Analecta Husserliana, vol 108. Springer Netherlands, Dordrecht, pp 183-192. https://doi.org/10.1007/978-94-007-0624-8_13

Grau C, Ginhoux R, Riera A, Nguyen TL, Chauvat H, Berg M, Amengual JL, Alvaro P-L, Ruffini G (2014) Conscious brainto-brain communication in humans using non-invasive technologies. PLoS One 9(8):1-6. https://doi.org/10.1371/journ al.pone.0105225. (Public Library of Science)

Hauskeller M, Curtis D, Carbonell, Thomas DP (2016) The Palgrave handbook of posthumanism in film and television. Springer, New York

Heylighen F (2013) From human computation to the global brain: the self-organization of distributed intelligence. In: Handbook of human computation, 1st edn. Springer, New York, pp 897-909

Husserl E (1952) Ideen Zur Einer Reinen Phänomenologie Und Phänomenologischen Philosophie. In: Biemel M (ed) Zweites Buch: Phänomenologische Untersuchungen Zur Konstitution. Husserliana, vol IV. Martinus Nijhoff, Leiden

Husserl E (1989) Ideas pertaining to pure phenomenology and to a phenomenological philosophy. Second book: studies in the phenomenology of constitution. Cllected Works, vol III. Kluwer Academic Publisher, Dordrecht

Husserl E, Fleischer M (1966) Analysen Zur Passiven Synthesis Aus Vorlesungs- Und Forschungsmanuskripten, 1918-1926. In: Fleischer M (ed) Husserliana, vol XI. M. Nijhoff, Den Haag

Husserliana V (1971) Ideen Zu Einer Reinen Phänomenologie Und Phänomenologischen Philosophie. In: Biemel M (ed) Drittes Buch: Die Phänomenologie Und Die Fundamente Der Wissenschaften. Husserliana, vol V. Martinus Nijhoff, The Hague

Hwang AD, Peli E (2014) An augmented-reality edge enhancement application for google glass. SID Symp Digest Tech Pap 45:305307. https://doi.org/10.1002/j.2168-0159.2014.tb00082.x

Ihde D (1990) Technology and the lifeworld. From garden to earth. Indiana University, Bloomington 
Ihde D (2003) Beyond the skin-bag. The brain extends its reach outside the body, so are we all cyborgs?" Nature 424:615

Ihde D (2008) Aging: I don't want to be a cyborg!. Phenomenol Cogn Sci 7(3):397-404. https://doi.org/10.1007/s11097-008-9096-0. (Springer Netherlands)

Kelly E (2011) Material ethics of value: Max Scheler and Nicolai Hartmann, vol 203. Springer Netherlands, Dordrecht. https://doi. org/10.1007/978-94-007-1845-6. (Phaenomenologica)

Kiourti A, Lee C, Volakis JL (2016) Fabrication of textile antennas and circuits with $0.1 \mathrm{Mm}$ precision. IEEE Antennas Wirel Propag Lett 15:151-153

Kiran AH, Verbeek P-P (2010) Trusting our selves to technology. Knowl Technol Policy 23:409-427. http://www.springerli nk.com/content/p068073x503q2342/fulltext.pdf. Accessed 23 Mar 2018

Kramer ADI, Jamie E, Guillory, Jeffrey TH (2014) Experimental evidence of massive-scale emotional contagion through social networks. Proc Natl Acad Sci 111(24):8788-8790. https://doi. org/10.1073/pnas.1320040111

Kyriazis M (2015a) Systems neuroscience in focus: from the human brain to the global brain? Front Syst Neurosci 9(7):1-4. https:// doi.org/10.3389/fnsys.2015.00007

Kyriazis M (2015b) Technological integration and hyperconnectivity: tools for promoting extreme human lifespans. Complex 20(6):1524. https://doi.org/10.1002/cplx.21626. (New York, NY: John Wiley \& Sons, Inc.)

Liberati N (2012) Between Leib and technology: a phenomenology of the living body's constitution. Glimpse 14:93-97

Liberati N (2014) Leib and technologies: relations and co-foundation. Investig Fenomenol 11:165-184

Liberati N (2016a) Augmented reality and ubiquitous computing: the hidden potentialities of augmented reality. AI Soc 31(1):17-28. https://doi.org/10.1007/s00146-014-0543-x (Springer London)

Liberati N (2016b) Technology, phenomenology and the everyday world: a phenomenological analysis on how technologies mould our world. Hum Stud 39(2):189-216. https://doi.org/10.1007/ s10746-015-9353-5 (Springer Netherlands)

Liberati N (2017) Teledildonics and new ways of "Being in Touch": a phenomenological analysis of the use of haptic devices for intimate relations. Sci Eng Ethics 23(3):801-823. https://doi. org/10.1007/s11948-016-9827-5 (Springer Netherlands)

Mack C (2015) The multiple lives of Moore's Law. Why Gordon Moore's grand prediction has endured for 50 years. Spectrum IEEE 52(4):31. https://doi.org/10.1109/MSPEC.2015.7065415

Mann S, Jason Nolan, Wellman B (2003) Sousveillance: inventing and using wearable computing devices for data collection in surveillance environments. Surveill Soc 1(3):331-355. http://www.surve illance-and-society.org. Accessed 23 Mar 2018

Menary R (ed) (2010) The extended mind. The MIT Press, Cambridge

Pais-Vieira M, Chiuffa G, Lebedev M, Yadav A, Miguel AL, Nicolelis (2015) Building an organic computing device with multiple interconnected brains. Sci Rep 5:11869+. https://doi.org/10.1038/ srep11869

Pettit P (2004) Groups with minds of their own. In: Socializing metaphysics: the nature of social reality. G-reference, information and interdisciplinary subjects series. Rowman \& Littlefield Publishers, Lanham

Pettit P (2014) Group agents are not expressive, pragmatic or theoretical fictions. Erkenntnis 79(9):1641-1662. https://doi.org/10.1007/ s10670-014-9633-x (Springer Netherlands)

Rhodes BJ, Minar N, Weaver J (1999) Wearable computing meets ubiquitous computing: reaping the best of both worlds. In: Proceedings of the 3rd IEEE International Symposium on Wearable Computers, 141. ISWC'99. IEEE Computer Society,
Washington, DC, USA. http://dl.acm.org/citation.cfm?id=51930 9.856497. Accessed 23 Mar 2018

Riva G, Gutiérrez-Maldonado J, Brenda KW (2016) Virtual worlds versus real body: virtual reality meets eating and weight disorders. Cyberpsychol Behav Soc Netw 19(2): 63-66. https://doi. org/10.1089/cyber.2016.29025.gri (Mary Ann Liebert, Inc.)

Roskies A (2005) We are Borg. Biol Philos 20:611-622. https://doi. org/10.1007/s10539-005-5593-5

Salice A (2015) Collective intentionality and the collective person in Max Scheler. In: Analytical and continental philosophy: methods and perspectives. De Gruyter, Berlin

Salice A, Taipale JH (2015) Group-directed empathy: a phenomenological account. J Phenomenol Psychol 46(2):163-184

Scheler M (1972) Die Idole Der Selbsterkenntnis. In: Max Scheler. Gesammelte Werke, vol III. Francke, Bern, pp 213-292

Scheler M (1973) Wesen Und Form Der Sympathie / Die Deutsche Philosophie Der Gegenwart: Gesammelte Werke. Gesammelte Werke (Max Scheler, 1874-1928). Bouvier Verlag, Bonn

Searle J (1990) Collective intentions and actions. In: Cohen PR, Morgan J, Pollack M (eds) Intentions in communication. MIT Press, Cambridge, pp 401-415

Selinger E, Engström T (2007) On nanatural embodied cyborg: identities, metaphors, and models. Janus Head 9(2):553-584

Selinger E, Engström T (2008) A moratorium on cyborgs: computation, cognition, and commerce. Phenomenol Cogn Sci 7(3):327-341. https://doi.org/10.1007/s11097-008-9104-4

Sobchack VC (1992) The address of the eye: a phenomenology of film experience. Princeton University Press, Princeton Paperbacks

Spence C, Okajima K, Cheok AD, Petit O, Michel C (2016) Eating with our eyes: from visual hunger to digital satiation. Brain Cogn 110:53-63. https://doi.org/10.1016/J.BANDC.2015.08.006 (Academic Press)

Stiegler B (2003) Our ailing educational institutions. Culture Macine 5. Cosmos Pub. Cooperative. http://www.culturemachine.net/index. $\mathrm{php} / \mathrm{cm} /$ article/viewArticle $/ 258 / 243$ ?iframe $=$ true $\&$ width $=100 \% 2$ 5\&height $=100 \% 25$

Summa M (2014) Spatio-temporal intertwining. Husserl's transcendental aesthetic, vol 213. Springer International Publishing, New York (Phaenomenologica)

Van Kleek M, O'Hara K (2014) The future of the social is personal: the potential of the personal data store. In: Miorandi D, Maltese V, Rovatsos M, Nijholt A, Stewart J (eds) Social collective intelligence: combining the powers of humans and machines to build a smarter society. Springer, Berlin

van den Eede Y (2015) Tracing the tracker. A postphenomenological inquiry into self-tracking technologies. In: Selinger E, Verbeek P-P (eds) Postphenomenological investigations: essays on humantechnology relations. Lexington Books, Lanham, pp 143-158

Verbeek P-P (2005) What things do. Philosophical reflections on technology, agency, and design. Penn State University Press, University Park

Verbeek P-P (2008) Cyborg intentionality: rethinking the phenomenology of human-technology relations. Phenomenol Cogn Sci 7(3):387-395

Verbeek P-P (2009) Philosophy of man and technology. http://www. utwente.nl/gw/wijsb/organization/verbeek/oratie_eng.pdf

Vertov D (1984a) The birth of the Kino-Eye. In: Kino-Eye: the writings of Dziga Vertov. University of California Press, Berkeley, pp 40-41

Vertov D (1984b) We: a variant of a Manifesto. In: Kino-Eye: the writings of Dziga Vertov. University of California Press, Berkeley, pp 5-9

Weiser M (1991) The computer for the 21st century. Sci Am 265(3):6675. http://www.ubiq.com/hypertext/weiser/SciAmDraft3.html. Accessed 23 Mar 2018 
Weiser M (1993a) Hot topics-ubiquitous computing. Computer 26(10):71-72. https://doi.org/10.1109/2.237456

Weiser M (1993b) Some computer science issues in ubiquitous computing. Commun ACM 36(7):75-84. https://doi.org/10.1145/15954 4.159617 (New York, NY: ACM)

Weiser M, Brown JS (1996) The Coming Age of Calm Technology. www.ubiq.com/hypertext/weiser/acmfuture2endnote.htm. Accessed 23 Mar 2018
Wellner GP (2015) A postphenomenological inquiry of cell phones: genealogies, meanings, and becoming. Lexington Books, Lehnam

Zimmer C (2015) Surveillance cinema. NYU Press, New York 